\title{
Anterior chamber depth - a predictor of refractive outcomes after age-related cataract surgery
}

\author{
Xiaona Ning ${ }^{1,2+}$, Yuhuan Yang ${ }^{2 \dagger}$, Hong Yan ${ }^{1,2^{*}}$ and Jie Zhang ${ }^{2}$
}

\begin{abstract}
Background: Anterior chamber depth (ACD) is becoming a hot topic and plays an important role in correcting the refractive errors (REs) after cataract surgery. The aim of this study was to assess the ACD changes and their relationship with the REs after phacoemulsification and intraocular lens (IOL) implantation in patients with age-related cataracts.

Methods: One hundred forty-five eyes of 125 age-related cataract patients from the Department of Ophthalmology, Tangdu Hospital, China, were recruited. IOL Master was used for axial length (AL) and the IOL power calculation measurements, and the Pentacam HR device was used for the ACD and lens thickness (LT) measurements. Every patient underwent uncomplicated phacoemulsification by a single surgeon using a single technique. Postoperative refraction results were obtained at 1 month. The appropriate formula used for the IOL power calculation was chosen depending on the AL, specifically the Hoffer $\mathrm{Q}(\mathrm{AL}<22.0 \mathrm{~mm}$ ), SRK TT $(22.0 \mathrm{~mm} \leq \mathrm{AL} \leq 30.0 \mathrm{~mm}$ ), and Haigis (AL $>30.0$ $\mathrm{mm})$ formulas.
\end{abstract}

Results: The postoperative ACD was deepened and tended to stabilize gradually after 2 weeks. A concurrent hyperopic shift $(0.57 \pm 0.47 \mathrm{D}$ ) was observed when the change in the ACD was less than $1.65 \mathrm{~mm}$, whereas a myopic shift $(-0.18 \pm$ $0.62 \mathrm{D})$ occurred contrarily, and the difference between the two groups was statistically significant $(P<0.0001)$. The change in ACD was significantly larger in the shallow anterior chamber $(1.92 \pm 0.40 \mathrm{~mm})$ than in the deep chamber $(1.33 \pm 0.42 \mathrm{~mm})(P<0.0001)$. Similarly, the change in ACD was larger in the short $\mathrm{AL}(2.12 \pm 0.37 \mathrm{~mm})$ than in the long $\mathrm{AL}$ $(1.32 \pm 0.49 \mathrm{~mm})$. The postoperative $A C D$ and refractive changes were correlated with the preoperative $A C D$ and $A L$ $(P<0.0001)$, respectively. Two regression formulas were proposed: postoperative $A C D=3.524+0.294 \times$ preoperative $A C D$ and postoperative $A C D=3.361+0.228 \times$ (preoperative $A C D+1 / 2 L T$ ).

Conclusions: The results of this study showed that the ACD deepened and was associated with a concurrent RE after cataract surgery. Postoperative changes in the ACD were related to the preoperative ACD and AL, which determined the refraction status and visual quality. The regression formula of the postoperative ACD could provide a theoretical basis for predicting refractive errors in the clinic.

Keywords: Cataract, Pentacam HR, Anterior chamber depth, Axial length, Refractive errors

\footnotetext{
* Correspondence: yhongb@fmmu.edu.cn

${ }^{\dagger}$ Xiaona Ning and Yuhuan Yang contributed equally to this work.

'Department of Ophthalmology, Xi'an No. 4 Hospital, Shaanxi Eye Hospital,

Affiliated Guangren Hospital School of Medicine, Xi'an Jiaotong University,

Xi'an 710004, Shaanxi Province, China

${ }^{2}$ Department of Ophthalmology, Tangdu Hospital, Fourth Military Medical

University, Xi'an 710038, Shaanxi Province, China
}

(c) The Author(s). 2019 Open Access This article is distributed under the terms of the Creative Commons Attribution 4.0 International License (http://creativecommons.org/licenses/by/4.0/), which permits unrestricted use, distribution, and reproduction in any medium, provided you give appropriate credit to the original author(s) and the source, provide a link to the Creative Commons license, and indicate if changes were made. The Creative Commons Public Domain Dedication waiver (http://creativecommons.org/publicdomain/zero/1.0/) applies to the data made available in this article, unless otherwise stated. 


\section{Background}

Cataract is one of the main reasons for visual impairment or loss worldwide [1], and the number of patients visually impaired was estimated by the WHO to be 95 million in 2014 [2]. Surgery with phacoemulsification and implantation of a posterior chamber intraocular lens (IOL) is the only effective treatment for managing cataract $[3,4]$. At present, with the rapid development of surgical and IOL technology, the goal of cataract surgery has changed from simply blindness relief simply to accurate refractive correction [5]. Therefore, refractive errors (REs) after cataract surgery resulting from IOL is one of the most urgent problems to be solved.

The postoperative RE is affected by many factors. The primary and most common sources include the measurement of the ocular parameters (keratometry, axial length (AL), lens thickness (LT), the selection of IOL calculation formula, the position of IOL implantation and so on [6], which determine the postoperative visual acuity of patients. To minimize postoperative RE, a comprehensive analysis of the above-mentioned biological characteristics should be performed [7]. Even though all these measurements are carried out, refractive corrections postoperatively are often needed, and the RE of 9 to $20 \%$ patients is more than 1 dioptre (D) [8]. Currently, it is believed that among the factors affecting postoperative visual function, the stability of the IOL postoperative position has recently been considered to be one of the key factors that can be represented by effective lens position (ELP) $[9,10]$. This means that improvement in refractive outcome requires better methods for predicting ELP.

The anterior chamber depth (ACD) refers to the distance between the anterior surface of the cornea and the anterior surface of the lens, which is an indicator of the axial position of the IOL (so-called ELP) postoperatively [11]. ELP could predict that forward deviation of the IOL leads to myopia, conversely leading to hyperopia [12]. Olsen found that $42 \%$ of IOL power prediction errors were caused by incorrect estimation of the postoperative ACD [13], which means that considering ACD into the calculation of the IOL power is probably an effective method to reduce postoperative errors. Among the existing calculation formulas of IOL power, SRK/T only measures the AL and keratometry, while the newer formulas (such as Haigis, Olsen, Holladay 2) often consider the preoperative ACD measurement, which is helpful in predicting the postoperative ELP and RE $[14,15]$. Therefore, ACD plays an important role in correcting the postoperative RE, which deserves further study. However, the way to access and predict postoperative ACD still remains unclear.

The purpose of this study was to assess the clinical and biometric parameters, especially $\mathrm{ACD}$, associated with postoperative RE after uneventful cataract surgery. For this purpose, we collected the clinical data of patients and followed up at least 1 month to analyse how the ACD influenced RE, to identify the key influencing factors and devise a way to predict postoperative ACD. These results are meaningful and may offer a better method of ELP prediction to help patients gain better vision quality after cataract surgery.

\section{Methods}

\section{Study design and patient selection}

In a retrospective study from July 2015 to January 2017, data from a total of 125 patients with age-related cataracts (145 eyes) referred to Tangdu Hospital affiliated with the Fourth Military Medical University in Xi'an, Shaanxi, were extracted. All research and measurements followed the tenets of the Declaration of Helsinki, and the protocol was reviewed and approved by the Ethics Committee of Tangdu Hospital (TDLL 201506-05). Informed consent was obtained before the research from all patients. Inclusion criteria were patients with agerelated cataracts who underwent phacoemulsification combined with in-the-bag IOL implantation without any operative accident. The exclusion criteria included a history of diseases affecting refraction, such as lacrimal duct diseases, glaucoma, corneal pannus, keratoconus, corneal oedema, pterygium, intraocular surgery; a history of fundus diseases, such as retinal detachment, retinal splitting, choroidal neovascularization, and vitreous haemorrhage.

\section{Surgical procedure}

Patients underwent a comprehensive physical examination and eye examination before surgery. Preoperatively, the clinical examination included optometry, intraocular pressure (IOP), fundus photography, anterior segment photography, B-ultrasound, OCT, corneal endothelial count, IOL master, visual electrophysiology, Pentacam, and routine blood tests. To prepare the eyes before surgery, patients were treated with bilateral levofloxacin eye drops $0.5 \%$ (Cravit, Santen, Japan) four times per day for 3 days to prevent infection. Then, patients were given tropicamide phenylephrine eye drops 0.5\% (Mydrin-P, Santen, Japan) to maximize pupil dilation beginning a half an hour before surgery. During the surgery, the same micro-incision phaco machine (Bausch \& Lomb, USA) was used by the same senior surgeon (Hong Yan). First, patients were anaesthetized topically with oxybuprocaine hydrochloride eye drops $1.0 \%$ (Benoxil, Santen, Japan), and then a $3.0 \mathrm{~mm}$ clear corneal incision was made at the steep meridian. A soft-shell technique was used to protect the corneal endothelium and maintain anterior chamber space. A centred circular continuous capsulorhexis with a diameter of $5.5 \mathrm{~mm}$ was 
made with capsulorhexis forceps. Then, thorough hydrodissection was performed to rotate the nucleus freely, and nuclear fracturing was performed using the stopchop method. After phacoemulsification, the posterior chamber IOL was implanted into the capsular. Different types of IOL were chosen depending on the different requirements of the patients. After surgery, patients were treated with levofloxacin eye drops $0.5 \%$ (Cravit, Santen, Japan) and prednisolone acetate ophthalmic suspension 1\% (Pred Forte, Allergan, Ireland) 4 times per day for 2 weeks after surgery. The postoperative clinical examination included optometry, IOP, and Pentacam 2 days, 2 weeks and 1 month after surgery.

\section{Data collection}

A questionnaire that included data about age, sex, AL, LT and $\mathrm{ACD}$ was completed for each patient based on their records. The ACD and AL were extracted from the biometry reports. The AL was measured with IOL Master 500 (Carl Zeiss, Germany), which was repeated five times for each patient, and the average AL was calculated by the machine. The LT and ACD were measured with a Pentacam HR Scheimpflug device 70,900 (OCULUS, Germany), which was calculated automatically by the machine. All these measurements were carried out by a trained medical worker. The results of Pentacam were extracted only when the quality of the examination showed "OK". The ACD we adopted here was determined based on the central inner corneal surface, perpendicular to the corneal surface to the most anteriorly visible part of the IOL. The $\mathrm{RE}$ calculated as the arithmetic deviation from the preoperative target refraction. The absolute refractive error refers to the absolute deviation between postoperative RE and preoperatively expected RE.

\section{Classification and measurements}

An $\mathrm{AL}<22.0 \mathrm{~mm}$ was considered short sighted, 22.0 $\mathrm{mm} \leq \mathrm{AL} \leq 26.0 \mathrm{~mm}$ was a normal $\mathrm{AL}$ and an $\mathrm{AL}>26.0$ $\mathrm{mm}$ was considered long sighted. For the ACD, we considered an $\mathrm{ACD}<2.66 \mathrm{~mm}$ as low depth and an $\mathrm{ACD} \geq$ $2.66 \mathrm{~mm}$ as high depth $(\mathrm{ACD}=2.66 \mathrm{~mm}$ was the median of the whole data). For the change in ACD, we separated the data into two groups: the A group (change of ACD $<$ $1.65 \mathrm{~mm}$ ) and the $B$ group (change of $A C D \geq 1.65 \mathrm{~mm}$ ) (change of $\mathrm{ACD}=1.65 \mathrm{~mm}$ was the median of the whole data). IOL Master was performed to determine an optimization formula for the IOL choice based on the AL. The IOL power was decided by obtaining the postoperative refraction at approximately -0.50 dioptre (D) with Hoffer Q $(\mathrm{AL}<22.0 \mathrm{~mm}), \mathrm{SRK} / \mathrm{T}(22.0 \mathrm{~mm} \leq \mathrm{AL} \leq$ $30.0 \mathrm{~mm})$, and Haigis $(\mathrm{AL}>30.0 \mathrm{~mm})$ formulas. Preoperative best-corrected visual acuity (BCVA) was recorded.

\section{Statistical analysis}

Data were analysed using SPSS version 19.0 (SPSS Inc., Chicago, IL, USA). One-way ANOVA was used to analyse differences between three groups. The independentsamples t-test was used to compare quantitative data between two groups when satisfying bivariate normal distribution, and if not, the Mann-Whitney $U$ test was used. The paired t-test was used to compare the preoperative and postoperative results of the same patient. The Pearson correlation coefficient was calculated to analyse the relationship between the quantitative data that satisfied the bivariate normal distribution. The Spearman correlation coefficient was calculated to analyse the univariate variables that satisfied the normal distribution. On the premise that the regression diagnostics were applied to test the validity of the linear regression models and the equations derived, the linear regression model was used to obtain a mathematical model to estimate postoperative ACD using preoperative $A C D$ and LT. All the data are displayed as the mean \pm standard deviation. A $p$-value of less than 0.05 was considered statistically significant.

\section{Results}

For the 125 cataract patients included whose Pentacam data were complete at 2 days, 2 weeks and 1 month postoperative, 145 cases (eyes) were studied overall, and 69 patients were men $(47.6 \%)$. The mean age of the patients was $67.7 \pm 11.5$ years. Of the patients whose Pentacam and optometry data were complete both preoperatively and 1 month postoperatively, 123 cases (eyes) were studied due to loss to follow-up, of which 60 cases were men (48.8\%), and their mean age was $67.8 \pm 10.1$ years. Regrettably, of the 123 cases, only 55 cases of LT were successfully measured preoperatively and 1 month postoperatively; 29 cases were men (52.7\%), and the mean age was $69.6 \pm 8.5$ years. All patients underwent uneventful surgeries without intraoperative or postoperative complications.

\section{Postoperative $A C D$ among different visits}

At 2 days, 2 weeks and 1 month postoperatively, the ACD was $4.16 \pm 0.59 \mathrm{~mm}, 4.32 \pm 0.52 \mathrm{~mm}$, and $4.31 \pm$ $0.53 \mathrm{~mm}$, respectively. There was a significant difference between 2 days and 2 weeks $(P=0.016)$ postoperatively, but there was no difference between 2 weeks and 1 month $(P=0.899)$ postoperatively. This indicated that the ACD tended to stabilize gradually 2 weeks postoperatively (Fig. 1). After phacoemulsification with a clear corneal incision, the ACD is relatively stable 2 weeks later. Therefore, we chose the postoperative 1 month period as the time point for collecting all the following data. 


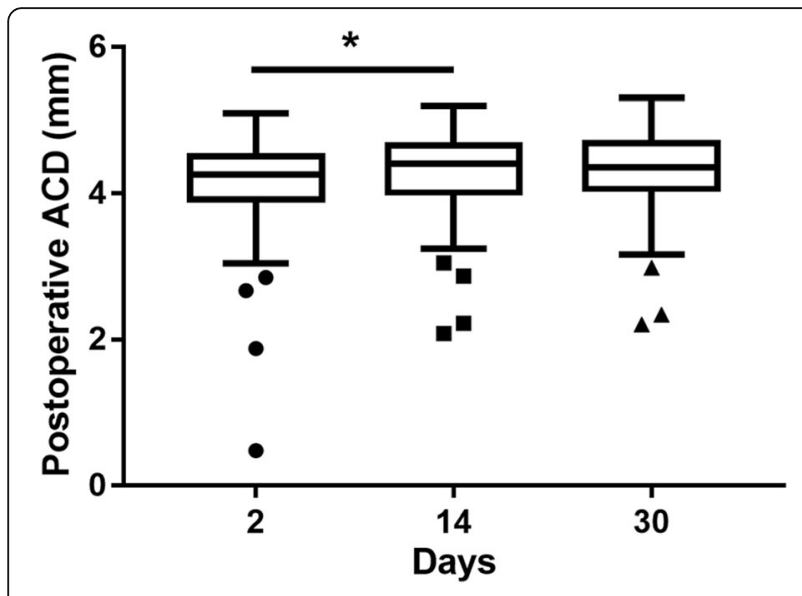

Fig. 1 Comparison of the postoperative ACD from different visits. ACD: anterior chamber depth. $\left({ }^{*} P=0.016, n=145\right)$

\section{Influence of ACD on refractive errors after cataract surgery}

The refractive errors of the A group (change in ACD $<$ $1.65 \mathrm{~mm}$ ) and the $\mathrm{B}$ group (change in $\mathrm{ACD} \geq 1.65 \mathrm{~mm}$ ) were $0.57 \pm 0.47 \mathrm{D}$ and $-0.18 \pm 0.62 \mathrm{D}$, respectively. The absolute refractive errors of the $\mathrm{A}$ and $\mathrm{B}$ groups were $0.60 \pm 0.43 \mathrm{D}$ and $0.44 \pm 0.48 \mathrm{D}$, respectively. As shown in Table 1, there was a significant difference in the refractive errors between the two groups $(P<0.001)$ but little difference in the absolute refractive errors $(P=0.049)$. This indicated that a hyperopia shift of refractive errors would often occur when the ACD had a less amount of change after cataract surgery, whereas a myopic shift was related to a greater change in the ACD.

Impact of the preoperative anterior chamber depth and axial length on the change of the postoperative anterior chamber depth and refractive errors

We regarded a preoperative $\mathrm{ACD}<2.66 \mathrm{~mm}$ as the A group and an $A C D \geq 2.66 \mathrm{~mm}$ as the $B$ group. As shown in Table 2, the changes in the postoperative ACD were $1.92 \pm 0.40 \mathrm{~mm}$ and $1.33 \pm 0.42 \mathrm{~mm}$, which were significantly different between the two groups $(P<0.001)$. The postoperative refractive errors were $-0.15 \pm 0.65 \mathrm{D}$ and $0.53 \pm 0.49 \mathrm{D}$, which were significantly different between the two groups $(P<0.001)$. However, there was no

Table 1 Comparison of refractive errors according to the classification of the change in anterior chamber depth

\begin{tabular}{lcll}
\hline Changes in ACD & N (eyes) & RE $(D)$ & Absolute RE $(D)$ \\
\hline A group $(<1.65 \mathrm{~mm})$ & 61 & $0.57 \pm 0.47$ & $0.60 \pm 0.43$ \\
B group $(\geq 1.65 \mathrm{~mm})$ & 62 & $-0.18 \pm 0.62$ & $0.44 \pm 0.48$ \\
$t$-value & & -7.44 & -1.99 \\
$P$-value & & 0.000 & 0.049 \\
\hline
\end{tabular}

$A C D$ anterior chamber depth, $D$ dioptre, $R E$ refractive error significant difference in the absolute refractive errors. The lower preoperative anterior chamber group varied more in the postoperative ACD.

With the classification of preoperative $\mathrm{AL}$, we regarded preoperative $\mathrm{AL}<22.0 \mathrm{~mm}$ as the A group, $22.0 \mathrm{~mm} \leq$ $\mathrm{AL} \leq 26.0 \mathrm{~mm}$ as the $\mathrm{B}$ group, and $\mathrm{AL}>26.0 \mathrm{~mm}$ as the $\mathrm{C}$ group. As shown in Table 3, the changes in the postoperative ACD were $2.12 \pm 0.37 \mathrm{~mm}, 1.59 \pm 0.44 \mathrm{~mm}$ and $1.32 \pm$ $0.49 \mathrm{~mm}$ for the three groups, respectively. The postoperative refractive errors were $-0.55 \pm 0.66 \mathrm{D}, 0.19 \pm 0.47 \mathrm{D}$ and $0.77 \pm 0.53 \mathrm{D}$ for the three groups, respectively. The postoperative absolute refractive errors were $0.59 \pm 0.62 \mathrm{D}$, $0.39 \pm 0.32 \mathrm{D}$ and $0.79 \pm 0.50 \mathrm{D}$ for the three groups, respectively. The overall change in ACD, refractive errors and absolute refractive errors were significantly different in the short AL compared to the normal AL $(P<0.05)$ and in the long $\mathrm{AL}(P<0.01)$. These data indicated that the postoperative change in the ACD was related to the preoperative ACD and AL.

Correlation analysis of the postoperative refractive errors As shown in Table 4, the Pearson correlation tests showed that there was a direct (linear) and positive relationship between the preoperative $\mathrm{ACD}$ and the postoperative refractive errors $(r=0.541 ; P<0.001)$ and between the AL and the refractive errors $(\mathrm{r}=0.574 ; P<0.001)$. Regarding the postoperative change in $A C D$, postoperative change of $A C D /$ preoperative ACD, postoperative change of $\mathrm{ACD} / \mathrm{AL}$ and $\mathrm{LT} /$ preoperative $A C D$, there was a direct (linear) and negative relationship between these and the postoperative refractive errors $(r=-0.642,-0.607,-0.698,-0.306$, respectively; $P<0.001)$. The postoperative ACD and LT were not correlated with the postoperative refractive errors $(P>0.05)$. The scatter plot in Fig. $2 \mathrm{a}$ also indicated that the postoperative change in ACD was negatively correlated with the postoperative refractive errors, which means that the postoperative refractive errors tended towards a myopic shift when the ACD changed a large amount (Fig. 2a). The scatter plot in Fig. $2 \mathrm{~b}$ also proved that the AL was positively correlated with the postoperative refractive errors, which means that the postoperative refractive errors tended towards a hyperopia shift when the AL was longer (Fig. 2b).

\section{Correlation analysis of the change of the postoperative anterior chamber depth}

As shown in Table 5, the Pearson correlation tests showed that there was a direct (linear) and negative relationship between the preoperative $\mathrm{ACD}$ and postoperative change in $\operatorname{ACD}(\mathrm{r}=-0.707 ; P<0.001)$ and between the AL and the refractive errors $(\mathrm{r}=-0.428 ; P<0.001)$. The postoperative ACD was directly (linear) and positively correlated with the postoperative change in ACD $(\mathrm{r}=0.368, P<0.001)$, as it was with the $\mathrm{LT} /$ preoperative ACD $(\mathrm{r}=0.674, P<0.001)$. The LT was not correlated 
Table 2 Comparison of the change in postoperative anterior chamber depth and refractive errors according to the classification of preoperative anterior chamber depth

\begin{tabular}{lllll}
\hline Preoperative ACD & N (eyes) & Changes in ACD $(\mathrm{mm})$ & RE (D) & Absolute RE (D) \\
\hline $\mathrm{A}(<2.66 \mathrm{~mm})$ & 61 & $1.92 \pm 0.40$ & $-0.15 \pm 0.65$ & $0.44 \pm 0.49$ \\
$\mathrm{~B}(\geq 2.66 \mathrm{~mm})$ & 62 & $1.33 \pm 0.42$ & $0.53 \pm 0.49$ & $0.60 \pm 0.42$ \\
$t$-value & & -7.88 & 6.55 & 1.77 \\
$P$-value & & 0.000 & 0.000 & 0.079 \\
\hline
\end{tabular}

$A C D$ anterior chamber depth, $D$ dioptre, $R E$ refractive error

with the postoperative change in $\operatorname{ACD}(P>0.05)$. The scatter plot in Fig. 3a proved that the preoperative ACD was negatively correlated with the postoperative change in ACD, which means that the postoperative ACD changed more when the preoperative ACD was shallower (Fig. 3a). The scatter plot in Fig. 3b proved that the AL was negatively correlated with the postoperative change in $A C D$, which means that the postoperative change in the $\mathrm{ACD}$ was greater when the AL was longer (Fig. $3 \mathrm{~b}$ ).

\section{Prediction of the postoperative anterior chamber depth}

A linear regression model was used to assess the relationship between the postoperative $\mathrm{ACD}$, preoperative ACD and LT. The following result was obtained: postoperative $\mathrm{ACD}=3.524+0.294 \times$ preoperative $\mathrm{ACD}$ (Fig. 4a); postoperative $\mathrm{ACD}=3.361+0.228 \times \quad$ (preoperative $\mathrm{ACD}+1 / 2 \mathrm{LT}$ ) (Fig. 4c); postoperative $\mathrm{ACD}$ was not correlated with the LT $(P>0.05$, Fig. 4b).

\section{Discussion}

Cataracts remain the leading cause of vision loss, and their prevalence increases with age. Cataract extraction and IOL implantation is an effective treatment, and the one most commonly used. With the development of technology, the purpose of surgery is not only to gain vision but also to see clearly and comfortably, which means allowing patients to have a better refractive status and visual experience [16]. Postoperative emmetropia is the major determining factor for patient satisfaction after cataract surgery. The ACD is an index that reflects the effective position of the IOL, which means that the prediction errors of the postoperative ACD will lead to a myopia or hyperopia shift after cataract surgery [17]. Therefore, ACD plays an important role in predicting postoperative RE after cataract surgery.

Our study demonstrated that cataract surgery deepens the ACD and that it tends to stabilize gradually 2 weeks after surgery. The change in the ACD derived from cataract surgery had an impact on refractive errors; a hyperopic shift would often occur when the change in the ACD was smaller, whereas a myopic shift was related to a larger change in the ACD. Next, we discussed the factors that influence changes in the ACD and found that the preoperative ACD and AL were related to changes in the ACD. Then, we performed a correlation analysis of the postoperative $\mathrm{RE}$ and the change in the ACD with some possible factors. The postoperative RE was negatively correlated with the postoperative changes in the ACD and positively correlated with the AL. Similarly, the postoperative changes in the ACD were negatively correlated with the preoperative ACD and AL. Furthermore, we proposed possible formulas for predicting the postoperative $\mathrm{ACD}$ : postoperative $\mathrm{ACD}=3.524+0.294 \times$ preoperative $\mathrm{ACD}$ and postoperative $\mathrm{ACD}=3.361+0.228 \times$ (preoperative $\mathrm{ACD}+1 / 2 \mathrm{LT}$ ). The possible reasons for our results are as follows.

There are different opinions about the period of time necessary to achieve postoperative refractive stability. The stability occurs between 2 weeks [18] and 6 weeks. We considered 1 month to be an acceptable period of time for postoperative refractive stability to develop. It has been reported that for each additional $1 \mathrm{~mm}$ change in the ACD, there is at least an extra $0.32 \mathrm{D}$ of refractive shift after cataract surgery [13]. Although the

Table 3 Comparison of the change in postoperative anterior chamber depth and refractive errors according to the classification of preoperative axial length

\begin{tabular}{lllll}
\hline AL $(\mathrm{mm})$ & $\mathrm{N}$ (eyes) & Changes in ACD (mm) & RE (D) & Absolute RE (D) \\
\hline $\mathrm{A}(<22.0)$ & 22 & $2.12 \pm 0.37^{\mathrm{a}}$ & $-0.55 \pm 0.66^{\mathrm{a}}$ & $0.59 \pm 0.62^{\mathrm{a}}$ \\
$\mathrm{B}(22.0-26.0)$ & 72 & $1.59 \pm 0.44$ & $0.19 \pm 0.47$ & $0.39 \pm 0.32$ \\
$\mathrm{C}(>26.0)$ & 29 & $1.32 \pm 0.49^{\mathrm{b}}$ & $0.77 \pm 0.53^{\mathrm{b}}$ & $0.79 \pm 0.50^{\mathrm{b}}$ \\
-value $^{\mathrm{a}}$ & & 0.000 & 0.000 & 0.040 \\
-value $^{\mathrm{b}}$ & & 0.008 & 0.000 & 0.000 \\
\hline
\end{tabular}

${ }^{\mathrm{a}}$ Comparison of $\mathrm{A}$ and $\mathrm{B}$ group

${ }^{\mathrm{b}}$ Comparison of $\mathrm{B}$ and $\mathrm{C}$ group

$A C D$ anterior chamber depth, $D$ dioptre, $R E$ refractive error 
Table 4 Correlation analysis of refractive errors

\begin{tabular}{llll}
\hline Correlative factors & N (eyes) & $r$ & $P$-value \\
\hline Preoperative ACD & 123 & 0.541 & 0.000 \\
Postoperative ACD & 123 & - & 0.178 \\
Postoperative changes in ACD & 123 & -0.642 & 0.000 \\
$\begin{array}{l}\text { Postoperative changes in ACD / } \\
\text { Preoperative ACD }\end{array}$ & 123 & -0.607 & 0.000 \\
Postoperative changes in ACD /AL & 123 & -0.698 & 0.000 \\
AL & 123 & 0.574 & 0.000 \\
LT & 55 & - & 0.595 \\
LT / Preoperative ACD & 55 & -0.306 & 0.023 \\
\hline
\end{tabular}

"-" means there is no correlation

$A C D$ anterior chamber depth, $A L$ axial length, $L T$ lens thickness, $r$ correlation coefficient

postoperative $\mathrm{ACD}$, which represented the IOL effective position, had been considered in the formula of the IOL power calculation, it was still affected by other factors causing the postoperative refractive status to be a myopic or hyperopic shift [19-23]. Most of the scholars and researchers agree that a postoperative refractive shift

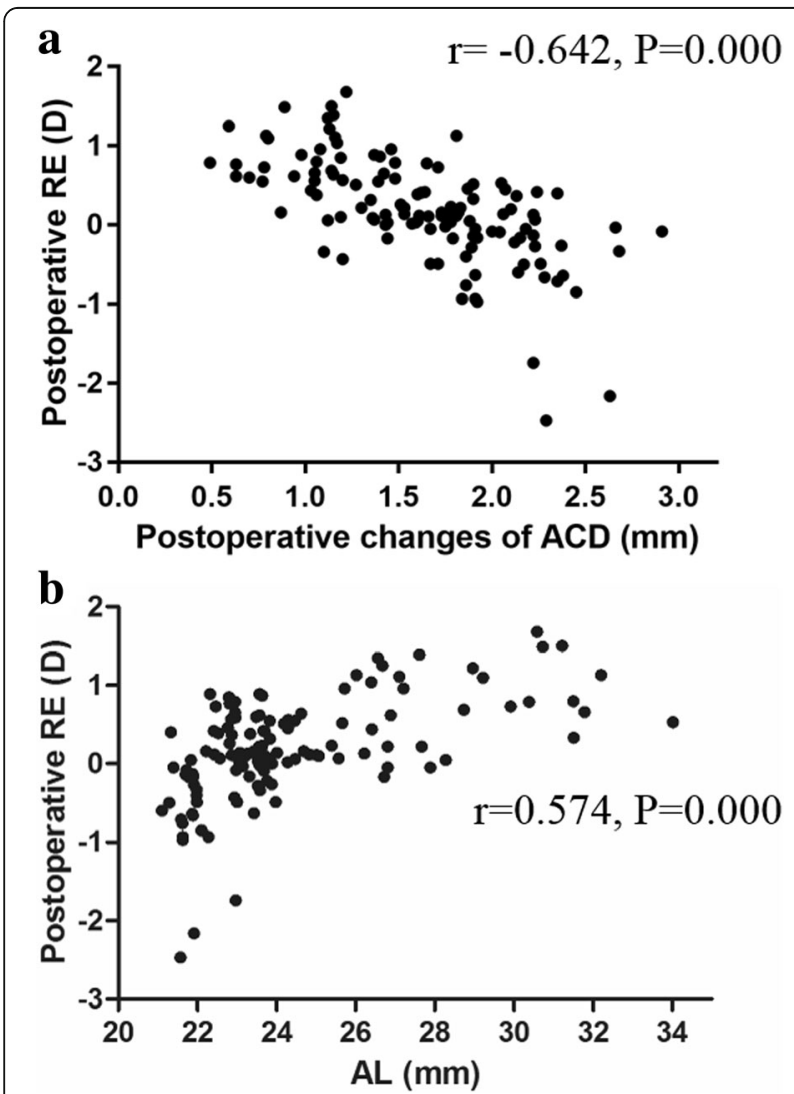

Fig. 2 Correlation analysis of the postoperative refractive errors. a The scatter plot of the relationship between the postoperative change in ACD and the postoperative RE. $\mathbf{b}$ The scatter plot of the relationship between AL and postoperative RE. $(n=123, P<0.001)$. ACD: anterior chamber depth; AL: axial length; D: dioptre; RE: refractive errors occurred and have studied this [24-26]; however, there has been no consistent opinion about the degree and the trend of this refractive shift. Our results indicated that a hyperopic or myopic shift often occurs with different degrees of change in the ACD.

Regarding the degree of change in the ACD after cataract surgery, some studies have reported that the depth of the preoperative anterior chamber is related to the postoperative ACD change [27]. Our study also proved that the changes in the ACD in the shallow and deep anterior chamber were $1.92 \pm 0.40 \mathrm{~mm}$ and $1.32 \pm 0.42 \mathrm{~mm}$, respectively, which implied that the postoperative change in the ACD was negatively related to the preoperative ACD. In addition, Muzyka-Wozniak [28] evaluated the postoperative ACD after phacoemulsification in eyes with a short or long axial length and found that the relative change in the ACD was larger in short eyes $(57 \%)$ than in normal eyes $(44 \%)$ or long eyes $(42 \%)$ $(P<0.017)$, which means that the AL influenced changes on the postoperative ACD. This finding was consistent with our study, which indicated that the changes in the ACD with short, normal and long AL were $2.12 \pm 0.37$ $\mathrm{mm}, 1.59 \pm 0.44 \mathrm{~mm}$ and $1.32 \pm 0.49 \mathrm{~mm}$, respectively, which indicated that the postoperative change in the ACD was also negatively related to the preoperative ACD. We next conducted a correlation analysis and proved this further. Taken together, the shallower the anterior chamber and the shorter the $\mathrm{AL}$ were, the greater were the changes in the ACD. Therefore, the refractive status of a patient with a shallow anterior chamber and a short AL would trend towards a myopic shift, conversely, a deep anterior chamber and long AL would move toward a hyperopic shift. We speculated that this phenomenon may result from a slight deviation in the ability the IOL Master formula to predict the IOL power. Because predicted postoperative ACD value of the patient with a shallow anterior chamber was larger and that of the patient with a long AL was smaller, the actual postoperative IOL, and the preoperative estimated position were not consistent. Thus, it raised the myopia or hyperopia refractive errors shift postoperatively.

Table 5 Correlation analysis of the change in postoperative anterior chamber depth

\begin{tabular}{llll}
\hline Correlative factors & N (eyes) & $r$ & $P$-value \\
\hline Preoperative ACD & 123 & -0.707 & 0.000 \\
Postoperative ACD & 123 & 0.368 & 0.000 \\
AL & 123 & -0.428 & 0.000 \\
LT & 55 & - & 0.211 \\
LT / Preoperative ACD & 55 & 0.674 & 0.000 \\
\hline
\end{tabular}

"-" means there is no correlation

$A C D$ anterior chamber depth, $A L$ axial length, $L T$ lens thickness, $r$ correlation coefficient 


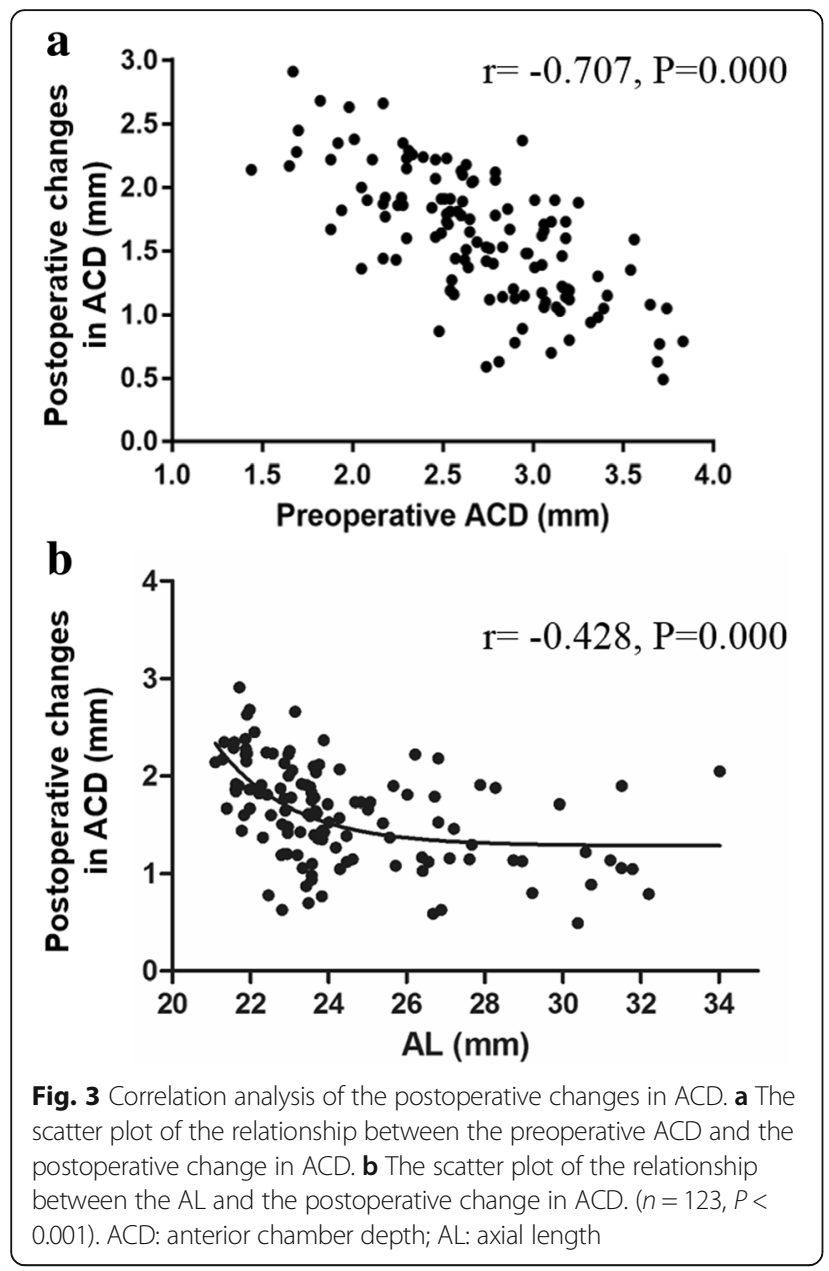

However, some studies differ from our results [29], and further studies will be needed.

The change in refractive status after cataract surgery is closely related to postoperative ELP. For the prediction of the postoperative ACD, Ucakhan et al. [30] noted an obvious backward shift of the iris at the beginning of the postoperative period, especially in eyes with very shallow anterior chambers. Pereira et al. [27] also found that the distance between the iris and IOL was increased over a period after cataract surgery, and the same result was observed by OCT in the anterior segment [31]. Although it is difficult to estimate the ELP after cataract surgery, researchers are still seeking a solution $[9,32$, 33]. A recent study showed that the preoperative $A C D$ demonstrated the greatest influence on the IOL calculation formulas, and the postoperative change in the ACD correlated significantly with errors of third generation formulas according to a simulated ACD [34]. In our study, we analysed the correlation between the postoperative and preoperative $\mathrm{ACD}$ and the results showed that postoperative $A C D$ was positively correlated with the preoperative ACD and "preoperative $\mathrm{ACD}+1 / 2 \mathrm{LT}$ ", but

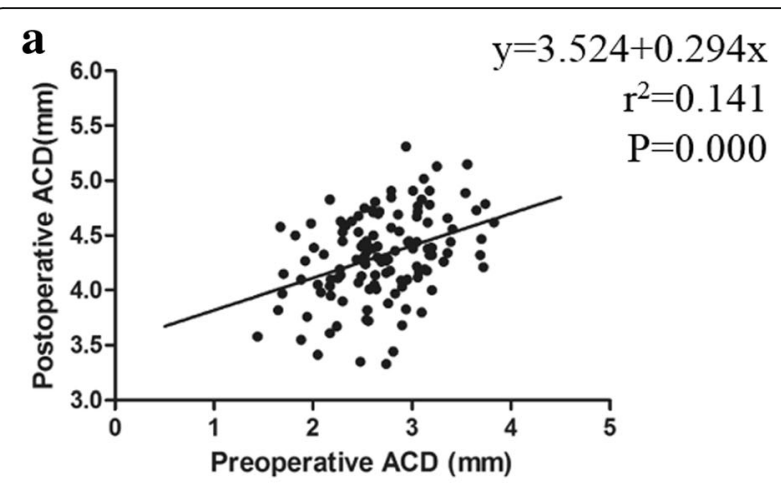

b
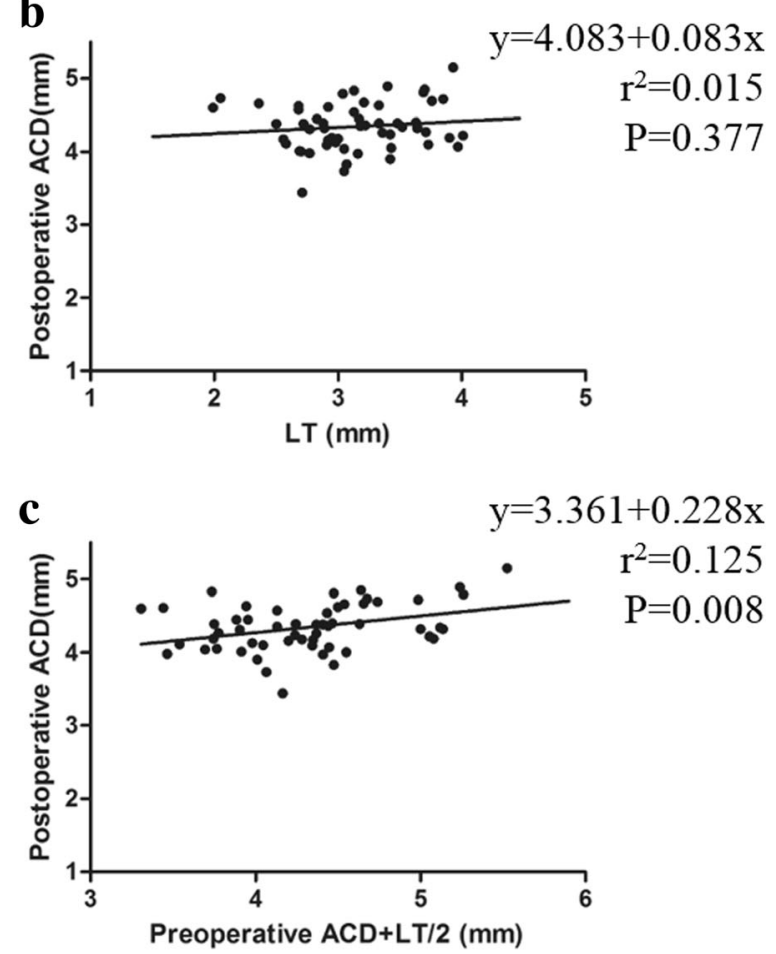

Fig. 4 Correlation analysis of the postoperative ACD. a The scatter plot of the postoperative ACD and the preoperative ACD. $(n=123, P<0.001)$; b The scatter plot of the postoperative ACD and LT. $(n=55, P>0.05)$; c The scatter plot of the postoperative ACD and preoperative ACD +1/2 $\mathrm{LT}$. $(n=55, P<0.01)$. ACD: anterior chamber depth; LT: lens thickness

there was no relationship with the LT. We considered the reason for the lack of correlation between the postoperative ACD and LT was that the expansion degree of the lens and the squeezing degree to the anterior chambers were different among the patients, which led to greater uncertainty about the IOL position.

The limitations of this study were that three different formulas that depended on a different AL to calculate the IOL were applied in this manuscript, which may itself induce a RE. The sample size was also small when we divided the subjects into three groups, especially for the $\mathrm{AL}<22.00 \mathrm{~mm}(n=22)$ and the $\mathrm{AL}>26.0 \mathrm{~mm}(n=$ 29) groups. Some of the patients were lost to follow-up 
because they could not adhere to the schedule, so we merely analysed the data from 1 month after surgery. Further studies are needed with a larger population, a longer follow-up period, and a multivariate regression of potential risk factors with one widely useful formula that can be adjusted to all AL.

\section{Conclusions}

In conclusion, our preliminary results suggested that the ACD played an important role in predicting postoperative RE after cataract surgery. A hyperopia shift would often occur when the change in the ACD was smaller, whereas a myopic shift was related to a larger change in the ACD, which determined the refraction status and visual quality. In addition, the regression formula of the ACD could provide a theoretical basis for predicting refractive errors in the clinic. Further prospective studies are needed to identify a widely useful formula for the clinical guidance of age-related cataract surgery.

\section{Abbreviations}

ACD: Anterior chamber depth; AL: Axial length; IOL: Intraocular lens; LT: Lens thickness; RE: Refractive errors

\section{Acknowledgements}

This work was supported by the Tangdu Hospital Grant for Clinical Innovation and the National Nature Science Foundation of China (No. 81570823). The authors thank Yu L. and other colleagues for assistance with the examination and collection of the data.

\section{Authors' contributions}

$X N$ and $Y Y$ collected and analysed the data of patients. XN wrote the manuscript. JZ advised on the data analysis and edited the manuscript. HY supervised the project and edited the manuscript. All authors have read and approved the final manuscript.

\section{Funding}

The National Nature Science Foundation of China (No. 81570823) was responsible for the examination and labour costs of the voluntary patients in this study during the data collection process.

\section{Availability of data and materials}

The datasets used and analysed during the current study are available from the corresponding author on reasonable request.

\section{Ethics approval and consent to participate}

The study protocol was reviewed and approved by the Ethics Committee of Ethics Committee of Tangdu Hospital of the Fourth Military Medical University, Xi'an, China (TDLL 201506-05). Written informed consent was obtained from all participants prior to study enrolment.

\section{Consent for publication}

Not applicable.

\section{Competing interests}

The authors declare that they have no competing interests.

Received: 23 October 2018 Accepted: 13 June 2019

Published online: 25 June 2019

\section{References}

1. Asbell PA, Dualan I, Mindel J, Brocks D, Ahmad M, Epstein S. Age-related cataract. Lancet. 2005;365(9459):599-609.

2. WHO, Visual impairment and blindness. 2014.
3. Riaz Y, Mehta JS, Wormald R, Evans JR, Foster A, Ravilla T, Snellingen T. Surgical interventions for age-related cataract. Am J Ophthalmol. 2006; 143(4):CD001323.

4. Iroku-Malize T, Kirsch S. Eye conditions in older adults: cataracts. FP Essent. 2016:445:17-23.

5. Nagy ZZ, McAlinden C. Femtosecond laser cataract surgery. Eye Vis (Lond). 2015;2:11.

6. Karabela Y, Eliacik M, Kocabora MS, Erdur SK, Baybora H. Predicting the refractive outcome and accuracy of $I O L$ power calculation after phacoemulsification using the SRK $T$ formula with ultrasound biometry in medium axial lengths. Clin Ophthalmol. 2017;11:1143-9.

7. Lee W, Bae HW, Lee SH, Kim CY, Seong GJ. Correlations between preoperative angle parameters and postoperative unpredicted refractive errors after cataract surgery in open angle Glaucoma (AOD 500). Yonsei Med J. 2017:58(2):432-8.

8. Nino $H$, Sahand AA, Sophie M, Oliver F. Predicting the postoperative intraocular lens position using continuous intraoperative optical coherence tomography measurements. Invest Ophthalmol Vis Sci. 2013;54(8):5196-203.

9. Zhong X, Long E, Chen W, Xiang W, Liu Z, Chen H, Chen J, Lin Z, Lin H, Chen W. Comparisons of the in-the-bag stabilities of single-piece and threepiece intraocular lenses for age-related cataract patients: a randomized controlled trial. BMC Ophthalmol. 2016;16:100

10. Norrby S. Sources of error in intraocular lens power calculation. J Cataract Refract Surg. 2008;34(3):368-76.

11. Gao Y, Dang GF, Wang X, Duan L, Wu XY. Influences of anterior capsule polishing on effective lens position after cataract surgery: a randomized controlled trial. Int J Clin Exp Med. 2015;8(8):13769.

12. Erickson P. Effects of intraocular lens position errors on postoperative refractive error. J Cataract Refract Surg. 1990;16(3):305-11.

13. Olsen T. Calculation of intraocular lens power: a review. Acta Ophthalmol Scand. 2007;85(5):472-85.

14. Engren AL, Behndig A. Anterior chamber depth, intraocular lens position, and refractive outcomes after cataract surgery. J Cataract Refract Surg. 2013; 39(4):572-7.

15. Plat J, Hoa D, Mura F, Busetto T, Schneider C, Payerols A, Villain M, Daien V. Clinical and biometric determinants of actual lens position after cataract surgery. J Cataract Refract Surg. 2017:43(2):195-200.

16. Zaidi FH, Corbett MC, Burton BJ, Bloom PA. Raising the benchmark for the 21st century--the 1000 cataract operations audit and survey: outcomes, consultant-supervised training and sourcing NHS choice. Br J Ophthalmol. 2007;91(6):731-6.

17. Fallah Tafti MR, Abdollah Beiki H, Mohammadi SF, Latifi G, Ashrafi E, Fallah Tafti Z. Anterior chamber depth change following cataract surgery in Pseudoexfoliation syndrome; a preliminary study. J Ophthalmic Vis Res. 2017;12(2):165-9.

18. Sugar A, Sadri E, Dawson DG, Musch DC. Refractive stabilization after temporal phacoemulsification with foldable acrylic intraocular lens implantation. J Cataract Refract Surg. 2001;27(11):1741-5.

19. Hayashi K, Hayashi H. Comparison of the stability of 1-piece and 3-piece acrylic intraocular lenses in the lens capsule. J Cataract Refract Surg. 2005; 31(2):337-42.

20. Behrouz MJ, Kheirkhah A, Hashemian H, Nazari R. Anterior segment parameters: comparison of 1-piece and 3-piece acrylic foldable intraocular lenses. J Cataract Refract Surg. 2010;36(10):1650-5.

21. Matsuda H, Kato S, Hayashi Y, Amano S, Hattori T, Yuguchi T, Kaiya T, Oshika T. Anterior capsular contraction after cataract surgery in vitrectomized eyes. Am J Ophthalmol. 2001;132(1):108-9.

22. Bang SP, Yoo YS, Jun JH, Joo CK. Effects of residual anterior lens epithelial cell removal on axial position of intraocular lens after cataract surgery. J Ophthalmol. 2018:2018:9704892.

23. Buehl W, Stojanac D, Sacu S, Drexler W, Findl O. Comparison of three methods of measuring corneal thickness and anterior chamber depth. Am J Ophthalmol. 2006;141(1):7-12.

24. Zhu X, He W, Sun X, Dai J, Lu Y. Fixation stability and refractive error after cataract surgery in highly myopic eyes. Am J Ophthalmol. 2016;169:89-94.

25. Su WW, Chen PY, Hsiao CH, Chen HS. Primary phacoemulsification and intraocular lens implantation for acute primary angle-closure. PLoS One. 2011;6(5):e20056.

26. Muthappan V, Paskowitz D, Kazimierczak A, Jun AS, Ladas J, Kuo IC. Measurement and use of postoperative anterior chamber depth of fellow eye in refractive outcomes. J Cataract Refract Surg. 2015;41(4):778-84. 
27. Pereira FAS, Cronemberger S. Ultrasound biomicroscopic study of anterior segment changes after phacoemulsification and foldable intraocular lens implantation. Ophthalmology. 2003;110(9):1799-806.

28. Muzyka-Wozniak M, Ogar A. Anterior chamber depth and iris and lens position before and after phacoemulsification in eyes with a short or long axial length. J Cataract Refract Surg. 2016;42(4):563-8

29. Yang F, Hou XR, Wu HJ, Bao YZ. Analysis of refractive status after cataract surgery in age-related cataract patients with shallow anterior chamber. Zhonghua Yan Ke Za Zhi. 2014;50(2):84-8.

30. Ucakhan OO, Ozkan M, Kanpolat A. Anterior chamber parameters measured by the Pentacam CES after uneventful phacoemulsification in normotensive eyes. Acta Ophthalmol. 2009;87(5):544-8.

31. Kucumen RB, Yenerel NM, Gorgun E, Kulacoglu DN, Dinc UA, Alimgil ML. Anterior segment optical coherence tomography measurement of anterior chamber depth and angle changes after phacoemulsification and intraocular lens implantation. J Cataract Refract Surg. 2008;34(10):1694-8.

32. Dooley I, Charalampidou S, Nolan J, Loughman J, Molloy L, Beatty S. Estimation of effective lens position using a method independent of preoperative keratometry readings. J Cataract Refract Surg. 2011;37(3):506-12.

33. Olsen T, Corydon L, Gimbel H. Intraocular lens power calculation with an improved anterior chamber depth prediction algorithm. J Cataract Refract Surg. 1995;21(3):313-9.

34. Jeong J, Song H, Lee JK, Chuck RS, Kwon JW. The effect of ocular biometric factors on the accuracy of various IOL power calculation formulas. BMC Ophthalmol. 2017;17(1):62.

\section{Publisher's Note}

Springer Nature remains neutral with regard to jurisdictional claims in published maps and institutional affiliations.

Ready to submit your research? Choose BMC and benefit from:

- fast, convenient online submission

- thorough peer review by experienced researchers in your field

- rapid publication on acceptance

- support for research data, including large and complex data types

- gold Open Access which fosters wider collaboration and increased citations

- maximum visibility for your research: over $100 \mathrm{M}$ website views per year

At $\mathrm{BMC}$, research is always in progress.

Learn more biomedcentral.com/submissions 